\title{
Severe Consumptive Coagulopathy in an Extremely-Low-Birth-Weight Infant with Intra- Abdominal Umbilical Vein Varix: A Case Report
}

\author{
Mitsuhiro Haga, MD ${ }^{1}$ Kanako Itoh, MD, PhD ${ }^{1}$ Tsuguhiro Horikoshi, MD, $\mathrm{PhD}^{2}$ \\ Fumihiko Namba, MD, PhD ${ }^{1}$ Kazuhiko Kabe, MD, MMA ${ }^{10}$ \\ ${ }^{1}$ Department of Pediatrics, Saitama Medical Center, Saitama Medical \\ University, Kawagoe, Saitama, Japan \\ 2 Maternal and Fetal Medicine, Center for Maternal, Fetal and \\ Neonatal Medicine, Saitama Medical Center, Saitama Medical \\ University, Kawagoe, Saitama, Japan \\ Address for correspondence Mitsuhiro Haga, MD, Department of \\ Pediatrics, Saitama Medical Center, Saitama Medical University, \\ 1981 Kamoda, Kawagoe, Saitama, 350-8550, Japan \\ (e-mail: haga_m@saitama-med.ac.jp).
}

Am J Perinatol Rep 2021;11:e76-e79.

\begin{abstract}
Keywords

- intra-abdominal umbilical vein varix

- consumptive coagulopathy

- extremely-low-birthweight infants

- intracranial hemorrhages

Intra-abdominal umbilical vein varix (IUVV) is a focal dilatation of the intra-abdominal umbilical vein. ${ }^{1}$ Most research defined IUVV as a focal dilatation over $9 \mathrm{~mm}$ or at least $50 \%$ larger than the intrahepatic portion. ${ }^{1}$ IUVV is a rare condition, reported at 0.5 to 2.5 per 1,000 pregnancies. ${ }^{1}$ Recent studies have shown favorable outcomes of isolated IUVVs in term neonates. ${ }^{1}$ However, the prognosis of IUVVs in preterm neonates is unclear due to the limited number of patients. We encountered a case of IUVV in an extremely low-birthweight infant (ELBWI) who developed severe consumptive coagulopathy after birth.
\end{abstract}

Recent studies have shown favorable outcomes for intra-abdominal umbilical vein varices (IUVVs) in term neonates who have no other complications. Little is known, however, about the prognosis of IUVVs in preterm neonates. We encountered a case of IUVV in an extremely low-birth-weight infant who developed severe consumptive coagulopathy after birth. The patient's coagulation test normalized as the varix spontaneously obstructed. Although life-threatening hemorrhagic complications were avoided, a cerebellum hemorrhage was found in the brain magnetic resonance imaging at the term-equivalent age. In a literature survey, coagulopathy was reported in 4 out of 15 infants with IUVVs born before 34 weeks of gestation, including our present case. Preterm infants with IUVVs may develop coagulopathy because of the prematurity of their coagulation-fibrinolysis systems. Attention should be given to the coagulation status of preterm neonates with IUVVs.

\section{Case}

The mother was a 32-year-old primigravida with a medical history of moyamoya disease. After confirmation of the pregnancy, she was referred to our hospital at 13 weeks of gestation because of her complication. Her pregnancy course had no abnormalities until the second half of second trimester. However, at 23 weeks of gestation, dilatation of the umbilical vein was detected in fetal ultrasonography. The umbilical vein was dilated from the abdomen to the umbilical portion of the portal vein, and the maximum diameter received

January 13, 2021

accepted after revision

February 15, 2021
DOI https://doi.org/

$10.1055 / \mathrm{s}-0041-1727288$

ISSN 2157-6998.

\footnotetext{
(C) 2021. The Author(s).

This is an open access article published by Thieme under the terms of the Creative Commons Attribution-NonDerivative-NonCommercial-License, permitting copying and reproduction so long as the original work is given appropriate credit. Contents may not be used for commercial purposes, or adapted, remixed, transformed or built upon. (https://creativecommons.org/ licenses/by-nc-nd/4.0/)

Thieme Medical Publishers, Inc., 333 Seventh Avenue, 18th Floor, New York, NY 10001, USA
} 


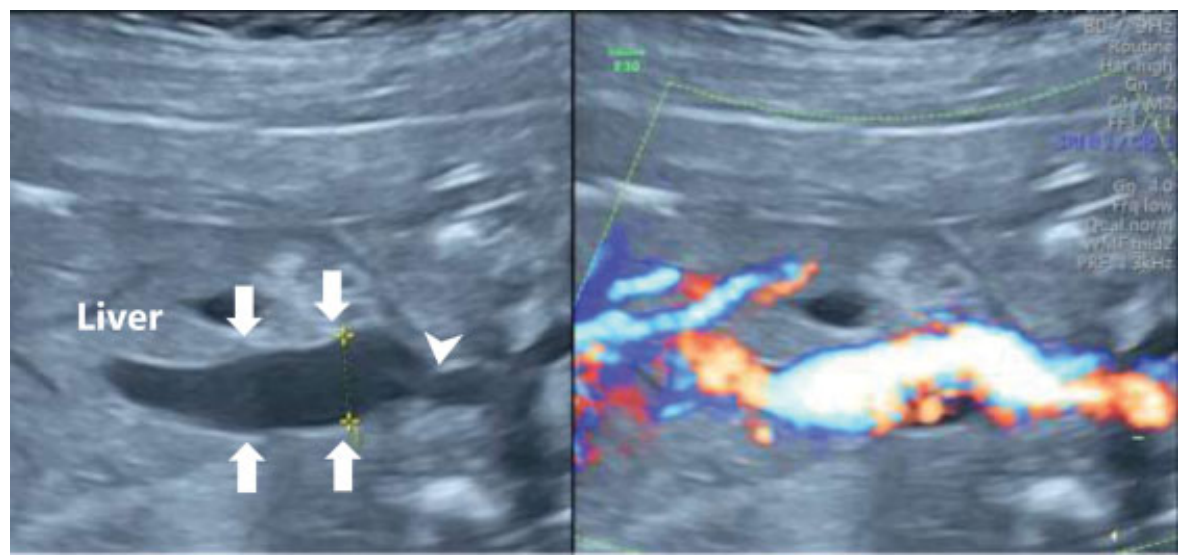

Fig. 1 Fetal ultrasonography showing the umbilical vein in the longitudinal axis. The dilated portion of the umbilical vein (arrow) extends from the umbilical ring (arrowhead) to the liver. The maximum diameter of the varix is $9.4 \mathrm{~mm}$. No turbulent flow was detected in color Doppler imaging.

was $9.4 \mathrm{~mm}$ (-Fig. 1). Fetal ultrasonography detected no other congenital abnormalities, and the case was followed with a weekly ultrasound. The diameter of the dilated portion of the umbilical vein remained unchanged, and the varix showed no thrombosis. From 25 weeks of gestation, fetal growth restriction and oligohydramnios were observed, and the mother was hospitalized for close observation of fetal status. At 27 weeks of gestation, severe prolonged deceleration was observed in cardiotocography. With a diagnosis of nonreassuring fetal status, an emergency cesarean section was performed.

A male infant was born with a birth weight of $613 \mathrm{~g}$. The Apgar scores were 3 at 1 minute and 8 at 5 minutes. With a diagnosis of respiratory distress syndrome, the infant received tracheal intubation and surfactant replacement therapy. Upon admission to our neonatal intensive care unit, he had petechiae all over the body and apparent bleeding from the venous and arterial insertion sites. The laboratory tests showed severe coagulopathy: prothrombin time $>55 \mathrm{sec}$ onds activated partial thromboplastin time $>180$ seconds fibrinogen $<20 \mathrm{mg} / \mathrm{dL}$, and D-dimer $26.3 \mu \mathrm{g} / \mathrm{mL}$. The complete blood count showed a low platelet level $(31,000 / \mu \mathrm{L})$. A large varix of the intra-abdominal umbilical vein was observed with abdominal ultrasonography after birth.

The infant was diagnosed with severe consumptive coagulopathy, and transfusions of fresh frozen plasma (FFP) and platelet concentrate (PC) were administered. The cause of his severe coagulopathy was considered the consumption of coagulation factors through the process of thrombus formation and fibrinolysis within the varix, but anticoagulant therapy was not performed because of his apparent bleeding tendency. His coagulation status gradually normalized as the varix was obstructed with thrombosis. PC and FFP transfusions were discontinued on days 1 and 3 of life, respectively.

The total closure of the varix was confirmed with ultrasonography on day 7 , and no thrombosis was found within the portal vein. After the closure of the varix, the patient had no recurrence of coagulopathy. The histopathology of the placenta and umbilicus showed no abnormality. Although he did not suffer from life-threatening hemorrhagic complications, a brain magnetic resonance imaging at term-equivalent age showed a small hemorrhage in the cerebellum. The patient was 18 months old (corrected age, 15 months) when this report was written and had achieved age-appropriate developmental milestones.

\section{Discussion}

To the best of our knowledge, this report is the first to present a case of IUVV in an ELBWI. Our patient developed severe coagulopathy requiring transfusion of FFP and PC. Fortunately, severe hemorrhagic complications did not occur except for a small cerebellar hemorrhage.

The etiology of IUVV is considered as a developing condition rather than a congenital abnormality. ${ }^{1}$ Most IUVVs develop in the extrahepatic portion within the abdomen, which is the weakest part of the umbilical vein. ${ }^{1}$ In earlier studies, fetal IUVVs were reported to be associated with the increased risk of intrauterine fetal death (IUFD). ${ }^{1}$ The causes of IUFD are unclear, but two possible mechanisms are speculated: (1) fetal cardiac failure due to excessive preload or (2) formation of thrombosis within the varix. ${ }^{2,3}$ Recent cohort studies have shown favorable outcomes in term neonates with isolated IUVVs; however, the prognosis of preterm neonates with IUVVs remains unclear.

To review the previous case reports of preterm neonates with IUVVs, we searched the Medline database with the words "umbilical vein varix," "umbilical vein aneurysm," "umbilical vein dilatation," or "umbilical vein ectasia." This search produced 583 citations from 1985 to 2019. We excluded the literature reporting cases of extra-abdominal UVVs $(n=15)$, portal vein anomalies $(n=9)$, vitelline veins $(n=6)$, umbilical artery aneurysms $(n=5)$, right umbilical veins $(n=1)$, and articles not relevant to IUVVs $(n=473)$. Thus, 74 publications were reporting IUVVs. From the 74 articles, we also excluded cases of non-neonates $(n=7)$, review articles without new cases $(n=2)$, a duplicate case $(n=1)$, and non-English articles $(n=7)$. Our final literature pool contained 57 articles, from which we reviewed 547 
Table 1 Reported cases of IUVV before 34 weeks of gestational age with or without complication of coagulopathy

\begin{tabular}{|c|c|c|c|c|c|c|c|}
\hline \multicolumn{4}{|c|}{ Cases without coagulopathy $(n=11)$} & \multicolumn{4}{|c|}{ Cases with coagulopathy (including the present case) $(n=4)$} \\
\hline Authors & GA (wk) & BW (g) & Complications & Authors & GA (wk) & BW (g) & Complications \\
\hline Mahony et al ${ }^{4}$ & 33 & 1984 & None & Vanrykel et al ${ }^{9}$ & 32 & NA & None \\
\hline Batton et al ${ }^{5}$ & 32 & 1098 & $\begin{array}{l}\text { Schistocytic } \\
\text { hemolytic anemia }\end{array}$ & Huber $^{10}$ & 33 & NA & Cerebral hemorrhage \\
\hline \multirow[t]{3}{*}{ Rahemtullah et al ${ }^{6}$} & 27 & 1280 & None & Ismail et al ${ }^{11}$ & 31 & 1515 & None \\
\hline & 28 & 1115 & $\begin{array}{l}\text { Atrial septal } \\
\text { defect }\end{array}$ & Present case & 27 & 613 & Cerebellar hemorrhage \\
\hline & 30 & 1670 & None & & & & \\
\hline Viora et $\mathrm{al}^{7}$ & 32 & 2150 & None & & & & \\
\hline \multirow[t]{2}{*}{ Fung et al ${ }^{8}$} & 33 & NA & Gastroschisis & & & & \\
\hline & 33 & NA & Gastroschisis & & & & \\
\hline $\begin{array}{l}\text { Kuwata and } \\
\text { Matsubara }\end{array}$ & 32 & 1804 & None & & & & \\
\hline Rosenblatt et al ${ }^{13}$ & 29 & NA & $\alpha$-thalassemia & & & & \\
\hline Ikeda et al ${ }^{14}$ & 32 & 1277 & None & & & & \\
\hline
\end{tabular}

Abbreviations: BW, birth weight; GA, gestational age; IUVV, intra-abdominal umbilical vein varix.

cases. Of the 547 cases, 19 were preterm infants born before 34 weeks of gestation, and detailed clinical data were available in 14 of these cases. ${ }^{4-14}$-Table 1 summarizes gestational age, birth weight, and complications of 15 cases, including the reported 14 cases and our present case. Gestational ages ranged from 27 to 33 weeks, and birth weights were 613 to 2,150 g. Neonatal death was reported in one case due to severe congenital anemia from $\alpha$-thalassemia. ${ }^{13}$ No patients had chromosomal abnormalities, but congenital anomalies were found in three cases (one case with an atrial septal defect and two cases with gastroschisis). ${ }^{6,8}$ Coagulopathy was reported in four cases (27\%), ${ }^{9-11}$ and two cases had intracranial hemorrhage. ${ }^{10}$ There were no apparent differences in gestational age and birth weight between the premature infants with coagulopathy and the ones without coagulopathy. No cases of coagulopathy or hemorrhagic complications were reported in neonates born after 34 weeks of gestation $(n=528)$.

This study does not demonstrate the actual incidence rates of coagulopathy in preterm and term infants with IUVVs. However, because the reports of IUVV cases with coagulopathy are limited to the neonates born before 34 weeks of gestation, preterm infants with IUVVs are considered more susceptible to developing coagulopathy. Coagulopathy associated with IUVVs is thought to be induced by the consumption of coagulation factors during thrombus formation and fibrinolysis within the varices. ${ }^{9}$ Preterm neonates have significantly lower coagulation factors and coagulation inhibitor activities than term neonates, ${ }^{15}$ and the presence of IUVV in a neonate with a premature coagulationfibrinolysis system may be associated with the development of coagulopathy.

We have reported on our first case of IUVV in an ELBWI infant who developed severe coagulopathy after birth. Other case reports of coagulopathy existed in preterm neonates with IUVVs. We should anticipate that preterm infants with IUVVs have a risk of developing coagulopathy.

\section{Informed Consent}

Informed consent was obtained from the patient's parents for the publication of this case report and any accompanying images.

\section{Disclosure}

The authors declare that they have no known competing financial interests or personal relationships that could influence the work reported in this paper.

\section{Conflict of Interest}

None declared.

\section{Acknowledgments}

The authors would like to show our appreciation to the nursing staff at Saitama Medical Center, Saitama Medical University, for their assistance in collecting the clinical data. We are also grateful to Dr. Hirotaka Ishido for his generous support for this study. We would also like to thank Dr. Ayumi Oshima, Dr. Shuntaro Oka, and Dr. Ayumi Sasaki for their valuable advice on this report. We also would like to thank Enago (www.enago.jp) for the English language review.

\section{References}

1 Jodi S, Dashe BLH. Ultrasound evaluation of the placenta, membranes, and umbilical cord. In: Mary E, Norton LMS, Vickie FeldsteinA, eds. Callen's Ultrasonography in Obstetrics and Gynecology, 6th edition. Philadelphia: Elsevier; 2017: 674-703 
2 Sepulveda W, Mackenna A, Sanchez J, Corral E, Carstens E. Fetal prognosis in varix of the intrafetal umbilical vein. J Ultrasound Med 1998;17(03):171-175

3 Fung TY, Leung TN, Leung TY, Lau TK. Fetal intra-abdominal umbilical vein varix: what is the clinical significance? Ultrasound Obstet Gynecol 2005;25(02):149-154

4 Mahony BS, McGahan JP, Nyberg DA, Reisner DP. Varix of the fetal intra-abdominal umbilical vein: comparison with normal. J Ultrasound Med 1992;11(02):73-76

5 Batton DG, Amanullah A, Comstock C. Fetal schistocytic hemolytic anemia and umbilical vein varix. J Pediatr Hematol Oncol 2000;22 (03):259-261

6 Rahemtullah A, Lieberman E, Benson C, Norton ME. Outcome of pregnancy after prenatal diagnosis of umbilical vein varix. J Ultrasound Med 2001;20(02):135-139

7 Viora E, Sciarrone A, Bastonero S, et al. Anomalies of the fetal venous system: a report of 26 cases and review of the literature. Fetal Diagn Ther 2004;19(05):440-447

8 Fung TY, Chan LW, Leung TY, Lau TK. Gastroschisis associated with an intra-abdominal umbilical vein varix: a report of 2 cases. Fetal Diagn Ther 2009;25(04):404-406

9 Vanrykel K, Bruneel E, Van Hoestenberghe MR, Buekenhout L, Gyselaers W, Theyskens C. Neonatal disseminated intravascular coagulation after thrombosis of a fetal intra-abdominal umbilical vein varix. J Obstet Gynaecol 2010;30(03):315

10 Huber G. Title page - intrahepatic umbilical vein varix with postnatal complication in the newborn. Ultraschall Med 2010; 31(01):1-3

11 Ismail $\mathrm{H}$, Chang YL, Chang SD, Nusee Z. Fetal intra-abdominal umbilical vein varix in monochorionic twins: is it significant? Malays J Med Sci 2012;19(03):69-73

12 Kuwata T, Matsubara S. Another "double bubble" sign or "double bladder" sign: fetal intra-abdominal umbilical vein varix. J Med Ultrason (2001) 2011;38(04):243

13 Rosenblatt J, Loberstajn A, Coulomb A, et al. Intra-abdominal umbilical vein varix associated with fetal cardiac failure: a pitfall to the prenatal diagnosis of $\alpha$-zero-thalassemia. Fetal Diagn Ther 2013;34(01):59-62

14 Ikeda M, Ueda A, Ueda A, Kawahara S, Fukuhara K, Hasegawa M. A case of foetal intra-abdominal umbilical vein varix with adjacent extra-abdominal vein constriction. J Obstet Gynaecol 2017;37 (08):1093-1095

15 Monagle P. Developmental hemostasis. In: Polin RA, Abman SH, Rowitch DH, Benitz WE, Fox WW, eds. Fetal and Neonatal Physiology. Fifth edition. Vol 2 Philadelphia, PA: Elsevier; 2017: 1151-1158 